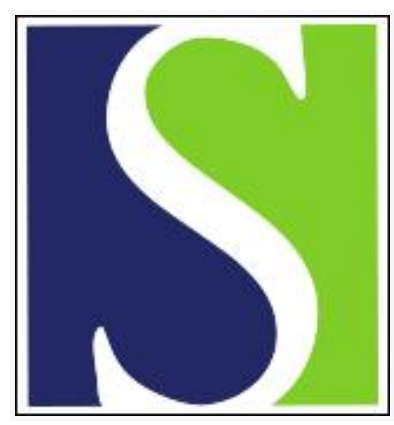

Scand J Work Environ Health 1998;24(6):503-507

https://doi.org/10.5271/sjweh.375

Issue date: Dec 1998

Powered dust respirator helmets in the prevention of occupational asthma among farmers

by Taivainen Al, Tukiainen HO, Terho EO, Husman KR

Key terms: agricultural worker; asthma; cow epithelium; dust respirator helmet; occupational disease; organic dust exposure

This article in PubMed: www.ncbi.nlm.nih.gov/pubmed/9988093

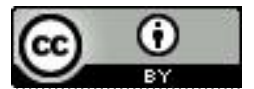




\title{
Powered dust respirator helmets in the prevention of occupational asthma among farmers
}

\author{
by Antti I Taivainen, MD, ${ }^{1}$ Hannu O Tukiainen, MD, ${ }^{+}$Erkki $O$ Terho, MD, ${ }^{2}$ Kaj $R$ Husman, $M D^{3}$
}

\begin{abstract}
Taivainen Al, Tukiainen HO, Terho EO, Husman KR. Powered dust respirator helmets in the prevention of occupational asthma among farmers. Scand J Work Environ Health 1998;24(6):503-507.

Objectives This study investigated the value of powered dust respirator helmets in the treatment of farmers with occupational asthma.

Methods The study population consisted of 33 asthmatic agricultural workers, 24 with occupational asthma induced by cow dander or grains, 2 with other forms of atopic asthma, and 7 with nonatopic asthma. The efficiency of a powered dust respirator helmet with a P2-class filter in preventing asthmatic symptoms was assessed for 1 year. Morning and evening peak expiratory flow rates and daily symptoms of the subjects were monitored for 3 months without the use of the helmet and for 10 months with the helmet.

Results Objective evidence of protection was obtained for farmers with occupational asthma. The morning peak flow rate increased and the variation in daily peak flow rate and the symptoms of cow-barn rhinitis diminished significantly during the helmet period. In the group of farmers with nonatopic asthma there was no improvement in peak flow rate or symptoms of asthma, although some of these farmers also seemed to benefit from helmet use. Conclusions The results of this study suggest that especially dairy farmers with occupational asthma benefit from the use of a powered dust respirator helmet.
\end{abstract}

Key terms agricultural workers, asthma induced by cow epithelium, dust respirator helmet, occupational diseases, organic dust exposure.

The most common forms of occupational respiratory disease among Finnish farmers are asthma caused by animal epithelia and farmer's lung. In 1996, 78 cases of farmer's lung and 107 cases of animal-derived occupational asthma, mostly due to bovine hair and dander, were diagnosed (1). In addition, there were 84 cases of occupational asthma caused by exposure to flour dust and 41 from exposure to storage mites in Finland.

The preventive use of dust respirators has been investigated for farmer's lung (figure 1). The results have shown that powered, $\mathrm{P} 2$-class filtered respirators can prevent the recurrence of disease (2-4).

The wearing of a powered dust respirator helmet has been recommended for asthmatic agricultural workers to reduce the harmful effects of organic dust in their work environment (5). The rather high price and running costs of the helmets have prevented their widespread use. Furthermore, their weight and large size may pose problems for some persons. Few controlled studies have been published on the benefits of dust respirator masks for patients with asthma.

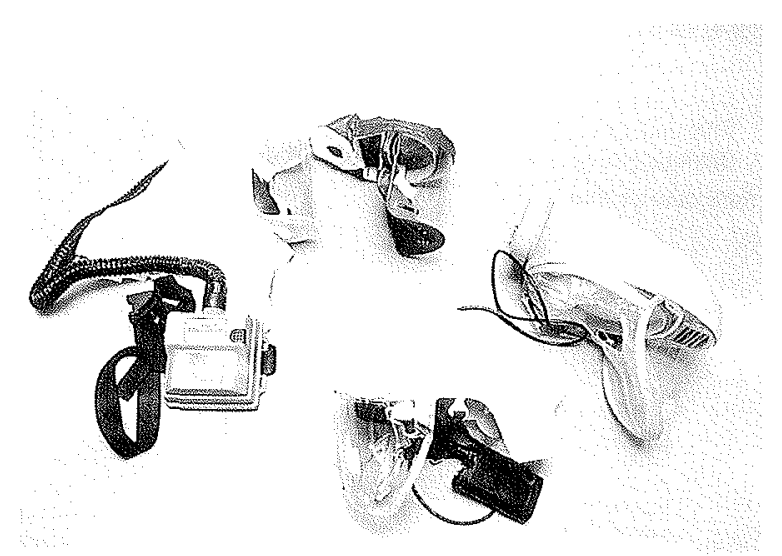

Figure 1. Powered dust respirator helmets.

1 Department of Pulmonary Diseases, Kuopio University Hospital, Kuopio, Finland.

2 Department of Clinical Allergology and Pulmonary Diseases, Turku University Hospital, Paimio, Finland.

3 Regional Institute for Occupational Health, Kuopio, Finland.

Reprint requests to: Dr Antti Taivainen, Department of Pulmonary Diseases, Kuopio University Hospital, PO Box 1777, FIN70211 Kuopio, Finland. [E-mail: antti.taivainen@kuh.fi] 
Laboratory animal workers and workers in an aluminum potroom have been shown to benefit from the wearing of powered dust respirator helmets $(6,7)$. We have studied the value of such helmets in the treatment of farmers with occupational asthma.

\section{Subjects and methods}

The study was prospective and included all patients with asthma induced by exposure to cow epithelium and treated in the Department of Pulmonary Diseases of the Kuopio University Hospital during 1987-1988. The helmets were provided as a form of medical rehabilitation for patients with occupational asthma, and later on they were also provided to a small number of patients with nonatopic asthma (table 1). All of the 21 cases induced by cow epithelium and the 3 cases induced by grain had been confirmed by bronchial challenge tests (8) with watersoluble allergen extracts (Allergologisk Laboratorium A/S, Copenhagen).

Allergens for skin-prick testing were commercial buffered-glycerol saline solutions (Allergologisk Laboratorium $\mathrm{A} / \mathrm{S}$ ). A wheel reaction with a mean diameter

Table 1. Characteristics of the patients.

\begin{tabular}{lrc}
\hline Characteristic & N & $\%$ \\
\hline Male & 18 & 55 \\
Female & 15 & 45 \\
Mean age (years) & 43 & \\
Smokers & 1 & 3 \\
Ex-smokers & 15 & 47 \\
Atopic asthma & 26 & 79 \\
Cow induced & 21 & 64 \\
Grain induced & 3 & 9 \\
$\quad$ Other atopic & 2 & 6 \\
Nonatopic asthma & 7 & 21 \\
\hline
\end{tabular}

of at least $3 \mathrm{~mm}$ was considered positive (9). A radioallergosorbent test (RAST) was considered positive if the titer was at least $0.35 \mathrm{U} / 1(10)$.

Skin-prick tests to bovine hair and dander were positive in 22 cases, and the RAST test against bovine epithelium was positive in 18 cases. The skin-prick test for grain (oats or barley) was positive in 4 cases, and the RAST against grain was positive in 3 cases. The RAST against storage mite, Lepidoglyphus destructor, was positive in 3 cases. The average total immunoglobulin $\mathrm{E}$ was 245 (range 24-1230) U/l for the atopic patients and 24 (range 7-61) U/l for the patients with nonatopic asthma.

All the patients recruited for the study were comprehensively trained in the use of the helmet during 3 sessions. Twenty-one Racal Airstream, 9 Racal Jupiter, and 2 Racal Dustmaster mk II respirators and 1 Racal Breathe Easy respirator were issued at the beginning of the follow-up. The technical data of these helmets are similar. The airflow varied from $1801 / \mathrm{min}$ (Racal Airstream) to $1201 / \mathrm{min}$ (Racal Jupiter). The weight of the face masks varied from 990 to $140 \mathrm{~g}$. During the follow-up, 1 Racal Jupiter and 3 Racal Air Stream protective helmets were changed to Racal Dustmasters since they caused the subjects to have neck problems. All the helmets were equipped with a P2-class filter, changed weekly together with the coarse prefilter. Active carbon filters were used in 7 cases. On the average, the helmet was in daily use for 4.6 (range $2-6$ ) hours.

During the follow-up, 31 patients were under regular antiinflammatory medication with inhaled corticosteroids. Two patients used beta-agonist therapy as their sole medication, while other patients used medication when needed. In addition, 11 patients used theophylline derivates perorally. The antiinflammatory medication remained unchanged during the study period. On the other hand, theophylline derivates and beta-agonists were reduced as the patient's condition permitted.
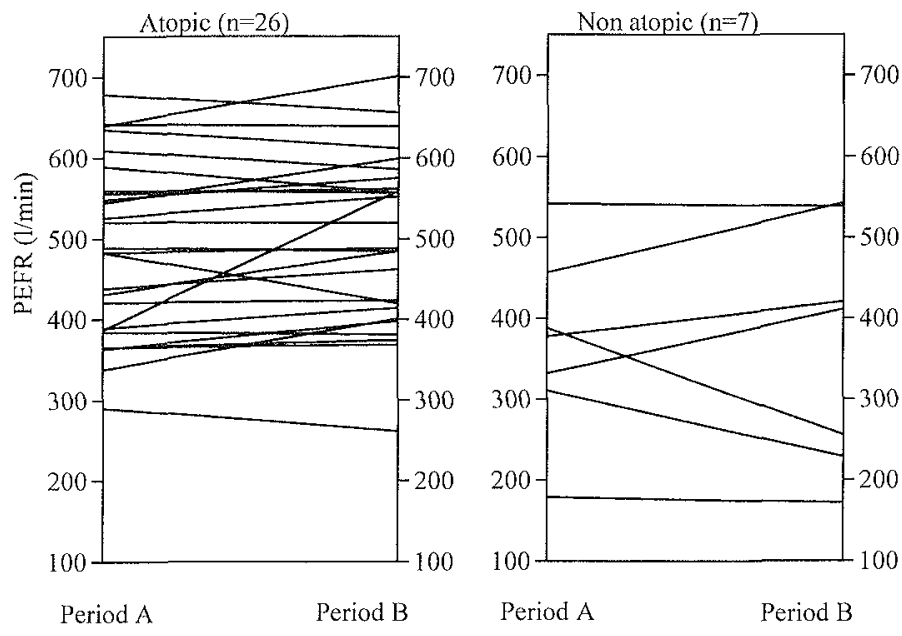

Figure 2. Morning measuremets of the peak expiratory flow rates (PEFR) of the atopic and nonatopic patients during the different monitoring periods. $(A=$ without helmet, $B=$ with helmet) 
Patients with atopic asthma were monitored for an average of 13.5 (range 12-18) months, of which 3 months were without the helmet and 10.5 months were with it. Patients with nonatopic asthma were monitored for 8.4 (range $4-10$ ) months, of which 2 months were without and 6.4 months were with the use of the helmet.

Thereafter, the patients were monitored routinely in the outpatient department, the last visit being an average of 3 years and 8 months after the beginning of the study.

During both periods of the study, the patients daily registered both their morning and evening peak expiratory flow rates (PEFR) (the best of 3 measurements). The morning PEFR values were obtained prior to medication and the evening values after full daily medication. In addition, patients daily recorded symptom scores in a diary. A 4-grade scale (none, mild, moderate, and severe) was used to classify the symptom parameters (wheezing, dyspnea, and cough). Sputum production was estimated in milliliters, and daily performance as the deviation from normal (normal, slightly restricted, moderately restricted, highly restricted).

Any increase in the symptoms felt by the patients was treated by additional beta-agonist inhalation, which was recorded in the symptom diary.

The registered parameters from both monitoring periods were compared. For the statistical analysis of the results, Student's t-test, a 2 -way variance analysis, and Wilcoxon's nonparametric test were used.

\section{Results}

In the atopic group, the methylxanthine medication of 4 patients was terminated during helmet use; all other medication remained unchanged. In the nonatopic group, the medication of 5 patients remained unchanged, while that of 1 patient was reduced and that of 1 other patient was increased during helmet use. When the helmet phase and the preceding period of equal length were compared, the number for corticosteroid treatments decreased from 18 to $2(\mathrm{P}<0.001)$. The mean number of sick leaves decreased from 18.5 to 5.2 days $(\mathrm{P}<0.001)$. These parameters did not change significantly among the farmers with nonatopic asthma.

Prior to the use of the dust respirator helmet, the asthma symptoms of all the patients were associated with the work environment. When they were wearing the helmet, work-related symptoms disappeared in 7 cases in the atopic group and in 1 case in the nonatopic group.

Neck problems associated with the use of the helmet were reported by 13 patients, for 4 of them to such an extent that helmet use occasionally became irregular.

When the mean PEFR values from the 2 follow-up periods were compared, a slight increase in the evening
PEFR, and a clearer increase in the morning PEFR $(\mathrm{P}<0.03)$ was recorded in the atopic group during helmet use (figure 2). In addition, the variation in the daily PEFR diminished significantly $(\mathrm{P}<0.02)$ (table 2$)$. Significant variation could not be observed when the PEFR measurements from October, February or July were compared. This finding indicated that the PEFR of the helmet users did not decrease during the indoor feeding period (September - April). The highest single increase in the morning and evening PEFR was observed for patients number 28 (with grain-induced asthma) and 12 (with cow-epithelium-induced asthma) (figures 3 and 4).

Four farmers whose asthma was induced by exposure to cow hair and dander and who had irreversible obstruction in their spirometry at the beginning of the study revealed a decrease in their mean PEFR values when wearing the helmet. Two of the 4 farmers with cow-epithelium-induced asthma and irregular use of the helmet showed a clear reduction in PEFR, while the remaining 2 showed no change during the follow-up periods.

In the nonatopic group, a slight reduction in both the mean morning and evening PEFR occurred, and the daily mean PEFR variation increased. The changes were not statistically significant (table 2). Nonetheless, 3 farmers with nonatopic asthma clearly benefited from the use of the respirator helmet.

Symptom monitoring revealed that the amount of daily sputum production among the atopic asthmatics was significantly reduced when the helmet was in use. A reduction in other mucosal symptoms was also observed, but these changes were not statistically significant (table 3 ). The mean daily number of supplementary beta-agonist inhalations was initially 0.32 (SD 0.42), and during the helmet period it was reduced to 0.24 (SD 0.53). The change was not however statistically significant.

In the group of patients with nonatopic asthma, the amount of mean daily sputum was 4.92 (SD 5.44) $\mathrm{ml}$ before the helmet was worn and 6.76 (SD 5.49) $\mathrm{ml}$ dur-

Table 2. Mean of the measurements of peak expiratory flow rate (PEFR) of the patients with atopic asthma $(\mathrm{N}=26)$ and those with nonatopic asthma $(\mathrm{N}=7)$ during the different monitoring periods $(\mathrm{N}=26)$.

\begin{tabular}{|c|c|c|c|c|c|}
\hline \multirow[t]{2}{*}{ Patient group } & \multicolumn{2}{|c|}{ Without helmet } & \multicolumn{2}{|c|}{ With helmet } & \multirow[t]{2}{*}{ P-value } \\
\hline & $\begin{array}{c}\text { PEFR } \\
(1 / \mathrm{min})\end{array}$ & $\mathrm{SD}$ & $\begin{array}{c}\text { PEFR } \\
(\mathrm{l} / \mathrm{min})\end{array}$ & SD & \\
\hline \multicolumn{6}{|l|}{ Atopic } \\
\hline Evening PEFR & 517 & 107 & 520 & 103 & NS \\
\hline Mean PEFR & 502 & 105 & 510 & 103 & NS \\
\hline Morning PEFR & 486 & 104 & 500 & 102 & $<0.03$ \\
\hline Variation in daily PEFR (\%) & 5.25 & 5.25 & 3.85 & 2.99 & $<0.02$ \\
\hline \multicolumn{6}{|l|}{ Nonatopic } \\
\hline Evening PEFR & 409 & 103 & 404 & 132 & NS \\
\hline Mean PEFR & 393 & 104 & 388 & 135 & NS \\
\hline Morning PEFR & 376 & 105 & 372 & 137 & NS \\
\hline Variation in daily PEFR (\%) & 8.46 & 3.38 & 8.71 & 6.22 & NS \\
\hline
\end{tabular}



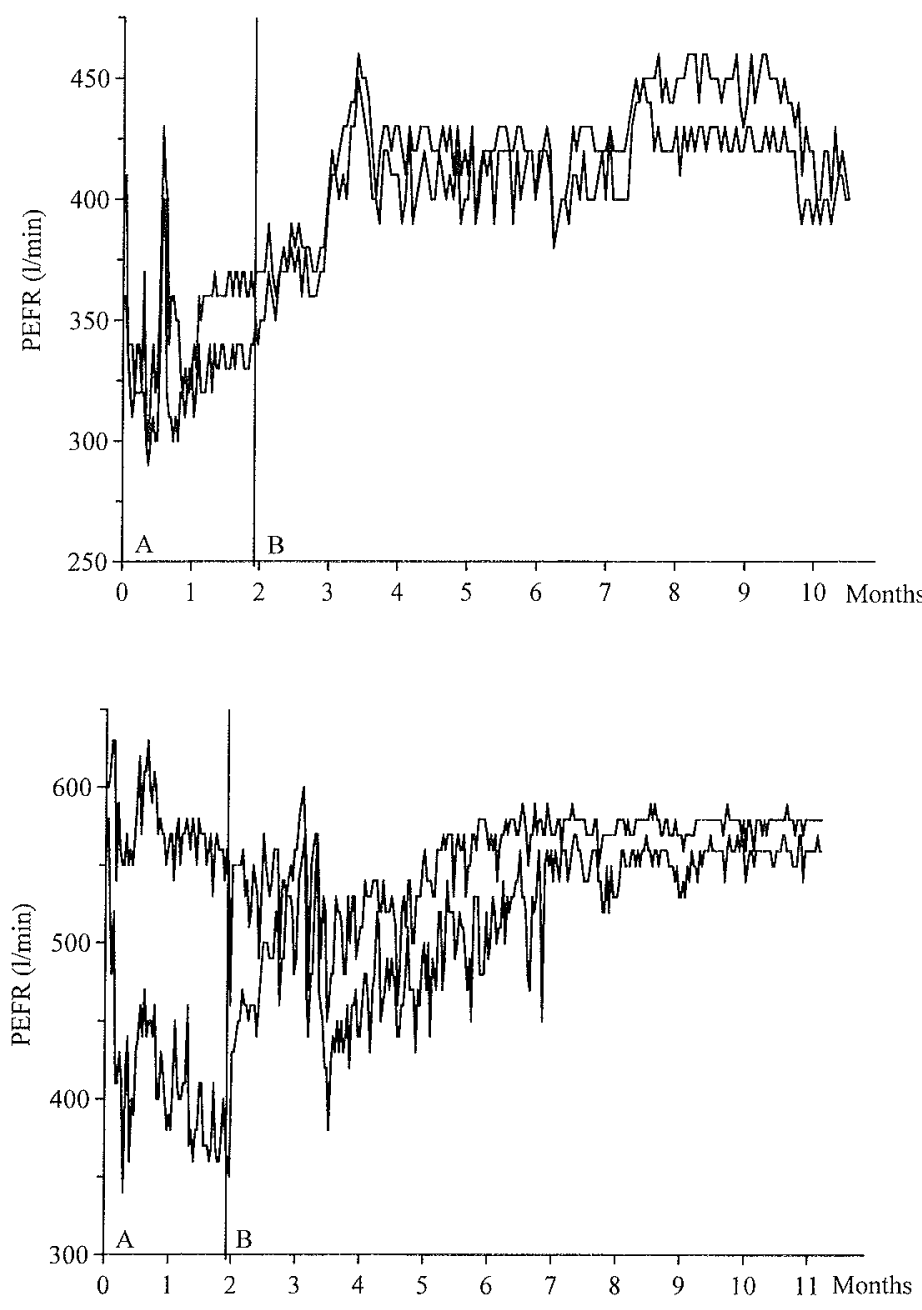

Figure 3. Morning and evening measurements of the peak expiratory flow rates (PEFR) of patient 28 during the different monitoring periods. $(A=$ without helmet, $B=$ with helmet, $\mathrm{P}<0.002$ ).
Table 3. Symptoms of the patients with atopic asthma $(\mathrm{N}=26)$ during the different monitoring periods.

\begin{tabular}{lccc}
\hline \multirow{2}{*}{ Symptom } & \multicolumn{2}{c}{ Cumulative symptom score } & P-value \\
\cline { 2 - 3 } & Without helmet & With helmet & \\
\hline Wheezing & 744 & 635 & NS \\
Dyspnea & 765 & 613 & NS \\
Cough & 759 & 619 & NS \\
Sputum production $(\mathrm{ml})$ & 3.48 & 2.59 & $<0.05$ \\
Daily performance & 680 & 698 & NS \\
\hline
\end{tabular}

ing the period with helmet use. The daily number of additional beta-agonist inhalations during the initial monitoring period was 0.33 (SD 0.32), and during the helmet period it was 0.77 (SD 1.19). Some mucosal symptoms were reduced, but some others seemed to worsen with the use of the helmet. However these changes were not statistically significant.

The recorded parameters were also compared by taking into account either only the results of the last week or those of the last month of both monitoring periods.
Figure 4. Morning and evening measurements of the peak expiratory flow rates (PEFR) of patient 12 during the different monitoring periods. $(A=$ without helmet $B=$ with helmet, $\mathrm{P}<0.001$ ).
However, these comparisons resulted in findings similar to those from the entire monitoring periods.

In the atopic group of patients before helmet use, 19 patients suffered from rhinitis while working in the barn, and, in 6 cases, the rhinitis was confirmed by challenge tests to be due to bovine allergens.

The use of the helmet reduced the symptoms of rhinitis in 17 of the rhinitis cases $(\mathrm{P}<0.001)$. Rhinitis even totally disappeared in 6 cases. In the group of nonatopic asthmatics, the incidence of rhinitis during work in a barn did not change.

During the poststudy follow-up period, none of the patients in the atopic group retired due to asthma. With respect to the nonatopic asthma group, 3 patients were awarded a disability pension because their asthma had worsened.

\section{Discussion}

The main purpose of this study was to evaluate the value of powered dust respirator helmets for farmers with oc- 
cupational asthma. The patient material was also supplemented with a small group of nonatopic asthmatic patients, since the recruitment of the occupational asthmatics advanced so slowly. The research was carried out as an open study because treatment periods with placebo respirator helmets were not considered ethically acceptable. Studies with relatively short follow-up periods have previously shown that asthmatic laboratory animal workers and workers in an aluminum potroom may benefit from wearing powered dust respirator helmets $(5,6)$.

In our study 3 different models of respirator helmets were used. The helmets were, however, technically very similar, and the change of helmet for some patients did not affect the results.

No seasonal effect on the PEFR could be found during helmet use. None of the patients who had a normal lung function at the beginning of the follow-up and who regularly used the helmet showed any deterioration in PEFR during the study. Almost all of the patients showed an immediate slight increase in PEFR during the first weeks of helmet use, with a subsequent slowly rising trend over the weeks.

On the basis of this study it can be concluded that farmers with occupational asthma benefit from the use of a powered dust respirator helmet. Furthermore, in our study, the wearing of helmets caused significant improvement in the rhinitis symptoms of patients with asthma induced by exposure to cow hair and dander. The wearing of the respirator helmet should be started as early as possible, and its use should be regular. The benefit from the use of the helmet was less marked for the patients with nonatopic asthma. The number of patients with nonatopic asthma was, however, very small. Furthermore, some of the patients suffered from rather severe asthma, and therefore some of these nonatopic asthmatics did not benefit from the use of the dust respirator helmet.

On the basis of this study, it can be recommended that powered dust respirator helmets be issued to all farmers with occupational asthma because there is no other effective means of removing all of the organic dust.

Furthermore, even very low concentrations of allergens can provoke symptoms in sensitive atopic asthmatics. In addition, some nonatopic asthmatic farmers seem to benefit from the use of a powered dust respirator helmet. However patients with severe asthma are rarely able to work in a cow barn even when wearing a helmet. Symptoms due to odors or fumes can be reduced by using active carbon filters. In order to ensure correct use, the respirator helmets should be chosen individually, and also sufficient personal guidance on their correct use is important.

\section{References}

1. Karjalainen A, Aalto L, Jolanki R, Keskinen H, Savela A. Occupational diseases in Finland 1996. Helsinki: Finnish Institute of Occupational Health, 1997.

2. Hendrick DJ, Marshall R, Faux JA, Krall JM. Protective value of dust respirators in extrinsic allergic alveolitis: clinical assessment using inhalation provocation tests. Thorax 1981;36:917-21.

3. Lacey J, Nabb S. Retention of actinomycete spores by respirator filters. Ann Occup Hyg 1982;25:351-63.

4. Nuutinen J, Terho EO, Husman K, Kotimaa M, Härkönen R, Nousiainen H. Protective value of powered dust respirator helmet for farmers with farmer's lung. Eur J Respir Dis 1987;71:212-20

5. Paky A, Knoblauch A. Staubbelastung, staubbedingte Lungenkrakheiten und Atem schutzmassnahmen in der Landwirtschaft. Schweiz Med Wochenschr 1995;125:458- 66.

6. Slovak AJM, Orr RG, Teasdale EL. Efficacy of the helmet respirator in occupational asthma due to laboratory animal allergy. Am Ind Hyg Assoc J 1985;46:411-5.

7. Kongerud J, Rambjor $O$. The influence of the helmet respirator on peak flow rate in aluminium potroom. Am Ind Hyg Assoc J 1991;52:243--8.

8. Cockroft DW, Ruffin RE, Frith PA, Cartier A, Juniper EF, Dolovich $J$, et al. Determinants of allergen-induced asthma: dose of allergen, circulating $\operatorname{IgE}$ antibody concentration, and bronchial responsiveness to inhaled histamine. Am Rev Respir Dis 1979;120:1053-8.

9. Dreborg S, editor. Skin tests used in type I allergy testing [position paper]. Allergy 1989;suppl 10:44.

10. Johansson $\mathrm{SGO}$, Bennich $\mathrm{H}$, Berg $\mathrm{T}$. In vitro diagnosis of atopic allergy, III: quantitative estimation of circulating IgE antibodies by the radioallergosorbent test. Int Arch Allergy 1971:41:443-7.

Received for publication: 9 December 1997 